FERREIRA FILHO, S.G. et al. Lúpus eritematoso discóide canino: relato de caso. PUBVET, Londrina, V. 8, N. 22, Ed. 271, Art. 1810, Novembro, 2014.

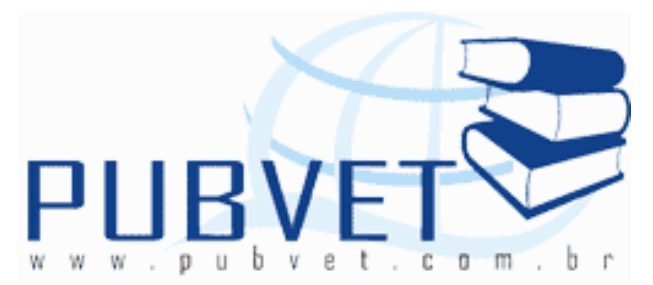

PUBVET, Publicações em Medicina Veterinária e Zootecnia.

\title{
Lúpus eritematoso discóide canino: relato de caso
}

\author{
Sinésio Gross Ferreira Filho ${ }^{1}$; Francisco Lucas Fernandes ${ }^{1}$; Marcelo Oliveira \\ Chamelete ${ }^{2}$; Rosyane Sousa Cruzeiro ${ }^{3}$
}

1 Graduando em Medicina Veterinária, Faculdade de ciências biológicas e da saúde UNIVIÇOSA/FACISA, Viçosa-MG, Brasil.

2 Médico Veterinário, Vitória-ES, Brasil.

3 Professora e Médica Veterinária, Faculdade de ciências biológicas e da saúde UNIVIÇOSA/FACISA, Viçosa-MG, Brasil.

\section{Resumo}

As doenças auto-imunes são consideradas raras em cães e gatos. Dentre elas, as mais frequentemente diagnosticadas são o pênfigo foliáceo e o lúpus eritematoso discóide ou cutâneo. O lúpus eritematoso discóide é considerado por alguns autores como uma variação benigna do lúpus eritematoso sistêmico, com manifestações clínicas restritas ao tegumento. A etiologia permanece incerta, mas vários fatores parecem influenciar para determinar o seu surgimento e dentre eles podemos citar a predisposição genética, envolvimentos hormonais, imunológicos e a radiação ultravioleta. Os sinais clínicos mais observados são despigmentação, eritema e descamação do plano nasal, podendo se expandir raramente para pina, periocular, junções mucocutâneas e condutos auditivos externos. O diagnóstico se baseia na anamnese, exame físico e histopatologia do tecido cutâneo afetado. $O$ tratamento consiste 
FERREIRA FILHO, S.G. et al. Lúpus eritematoso discóide canino: relato de caso. PUBVET, Londrina, V. 8, N. 22, Ed. 271, Art. 1810, Novembro, 2014.

na aplicação tópica e/ou sistêmica de corticosteróides e protetor solar nas áreas despigmentadas. O presente trabalho visa relatar um caso de lúpus eritematoso discóide em um cão da raça pastor alemão, com 4 anos de idade e otite bilateral recorrente, arresponsiva ao tratamento com solução otológica à base de enrofloxacino, sulfadiazina de prata e hidrocortisona. Ao exame físico foram notados meneios de cabeça, condutos auditivos externos eritematosos, doloridos e de fácil sangramento à otoscopia, além de despigmentação e lesões erodidas em comissuras nasais. Com base nos achados do exame clínico foi possível suspeitar de doença auto-imune, sendo o LED confirmado pela histopatologia das lesões em comissuras nasais. O paciente até a presente data apresenta remissão total das lesões em plano nasal e do quadro de otite externa bilateral.

Palavras-chave: corticosteróides; dermatologia; imunorreatividade.

\section{Canine discoid lupus erythematosus: case report}

\section{Abstract}

Autoimmune diseases are considered to be rare in dogs and cats. Among them, the most commonly diagnosed are pemphigus foliaceus and discoid or cutaneous lupus. The discoid lupus erythematosus is considered by some authors as a benign variation of systemic lupus erythematosus with clinical manifestations restricted to the tegument. The etiology remains unclear, but several factors seem to influence to determine the beginning and among them we can mention genetic predisposition, hormonal involvement, immunological and ultraviolet radiation. The most common clinical signs are depigmentation, erythema and scaling of the nose and may expand to more rarely ear, periocular, mucocutaneous junctions and external auditory canal. The diagnosis is based on history, physical examination and histopathology the cutaneous tissue affected. Treatment consists of topical and/or systemic corticosteroids and application of sunscreen on depigmented areas. This paper describes a case of discoid lupus erythematosus in a german sheepdog, 4 
FERREIRA FILHO, S.G. et al. Lúpus eritematoso discóide canino: relato de caso. PUBVET, Londrina, V. 8, N. 22, Ed. 271, Art. 1810, Novembro, 2014.

years old, history of injury in the nose, bilateral and recurrent otitis unresponsive to treatment with ear solution based on enrofloxacin. On physical examination head waggle, erythema and pain on palpation of the external auditory canal were noted. Based on the findings of the clinical examination was possible suspect autoimmune disease, confirmed by histopathological examination. The treatment was based on topical steroids and elimination of perpetuating factors of recurrent otitis, the patient in question had complete remission of injuries.

Keyword: corticosteroids; dermatology; immunoreactivity.

\section{INTRODUÇÃO:}

O lúpus eritematoso discóide (LED) é a segunda doença dermatológica auto-imune mais frequentemente diagnosticada em cães (GERHAUSER et al., 2006; SCOTT et al., 1996). Essa dermatopatia é considerada rara em cães e gatos (SCOTT et al., 1996), contrapondo, Gross et al., (2009) relata o LED como sendo uma dermatopatologia auto-imune de ocorrência não tão rara em cães.

As raças caninas mais comumente afetas são Pastores Alemães, Pointers Alemães de pêlo curto, Collie, Afghan Hounds, Beagles, Poodles, Pastor de Shetland e Huski Siberiano (RHODES, 2003; SCOTT et al., 1996; THOMPSON, 1997).

Segundo Rhodes (2003) e Scott et al., (1996) não há indícios de predisposição sexual e etária, entretanto, Thompson (1997) relata maior incidência em cães com faixa etária média de 6 anos.

Apesar de múltiplos fatores envolvidos, a predisposição genética parece contribuir significativamente na ocorrência de auto-imunidade (BALDA et al., 2002).

O LED é considerado uma variação benigna do Lúpus Eritematoso Sistêmico (LES), ou seja, não apresenta envolvimento sistêmico, sendo restrito ao tecido cutâneo (FENNER, 2003; GROOTERS, 2003; LARSSOM E OTSUKA, 2000; ROSENKRANTZ, 2005; SCOTT et al., 1996; TIZARD, 2002). 
FERREIRA FILHO, S.G. et al. Lúpus eritematoso discóide canino: relato de caso. PUBVET, Londrina, V. 8, N. 22, Ed. 271, Art. 1810, Novembro, 2014.

Apesar da fisiopatologia do LED estar bem elucidada, a etiologia permanece incerta (WERNER, 1999), sendo de ocorrência multifatorial e heterogênea, com predisposição genética, envolvimento viral, hormonal e exposição à radiação ultravioleta UVA e UVB, levando a produção de anticorpos autorreativos, ou seja, direcionados contra constituintes próprios do organismo, culminando com um processo inflamatório crônico (BALDA et al., 2002; BERBERT e MANTESE, 2005; COSTNER e SONTHEIMER, 2003; SCOTT et al., 1996).

A radiação solar incita ou exarceba o quadro em um número considerável de animais, podendo ocorrer piora das lesões no verão. (IWASAKI et al., 1995; RHODES, 2003; SCOTT et al., 1996).

A predisposição genética, envolvimento viral, hormonal e exposição à radiação utravioleta acabam contribuindo com a alteração da regulação imunológica mediada pelas células $T$, exarcebação da atividade de linfócitos $B$ e inibição da atividade de linfócitos $T$ supressores, anticorpos autorreativos são produzidos anormalmente, formação de imunocomplexos e interação com o sistema complemento, levando ao estabelecimento do LED e intenso processo inflamatório (NETO e BONFÁ, 2006). Quando a radiação solar incide sobre a epiderme de um indíviduo geneticamente predisposto e atinge a camada basal da epiderme, há uma indução no aumento da expressão de auto-antigenos na camada superficial da membrana celular dos ceratinócitos. Os Auto-anticorpos específicos que irão se ligar ao ceratinócito são encontrados no fluido tecidual que banha a epiderme. Essa ligação incita citotoxicidade ao ceratinócito, o que leva a liberação de vários mediadores inflamatórios que por sua vez vão promover quimiotaxia de linfócitos, tais como interleucinas I, II, III, VI, VIII, fator de necrose tumoral alfa (TNF- a), e ainda os agentes estimuladores de macrófagos, monócitos e granulócitos (LARSSOM e OTSUKA, 2000; SCOTT et al., 1996).

No LED, Segundo Scott et al., (1996), parece ocorrer deficiência de células $T$ supressoras associada a hiperresponsividade de células $B$ e déficit de componentes do sistema complemento. Larssom (2005), Lawall et al., (2008) 
FERREIRA FILHO, S.G. et al. Lúpus eritematoso discóide canino: relato de caso. PUBVET, Londrina, V. 8, N. 22, Ed. 271, Art. 1810, Novembro, 2014.

e Val (2006), relatam o LED como sendo uma dermatopatia auto-imune que envolve as reações de hipersensibilidade do tipo II e III, culminando com produção de auto-anticorpos contra constituintes próprios da pele e formação de imunocomplexos no tecido cutâneo, sendo este último, segundo Val (2006) o responsável pelos sinais clínicos do LED.

Visando explicar o aparecimento dos 5 principais tipos de lesões do LED, Larssom e Otsuka (2000) e Scott et al., (1996), descreveram uma hipótese: fotossensibilidade, sendo as lesões geradas em conseqüência da radiação solar; insulto aos ceratinócitos, mediada por linfócitos $\mathrm{T}$ e macrófagos; infiltração linfocítica, síntese de anticorpos auto-reativos e depósito de imunocomplexos.

Diferentemente do que ocorre em humanos, onde há infiltração predominante de linfócitos T nas lesões tegumentares, seja no LES ou LED; nos cães há predomínio de plasmócitos, sugerindo que estes possam ter um envolvimento significativo na imunopatogenia do LED. Todavia, não sabe-se exatamente o papel dos linfócitos $B$ e plasmócitos na patogenia do LED (GERHAUSER et al., 2006).

As lesões cutâneas mais comumente observadas são eritema, despigmentação e descamação de plano nasal (GERHAUSER et al., 2006; GROSS et al., 2009), em casos raros pode expandir para extremidades distais, junções muco-cutâneas, periocular e pina (GERHAUSER et al., 2006; SCOTT et al., 1996). Com a evolução do quadro as lesões podem apresentar-se erosivas, ulceradas e crostosas, podendo evoluir para alopecia e cicatrização (RHODES, 2003; SCOTT et al., 1996). O grau e intensidade do prurido e dor podem variar (SCOTT et al., 1996). Segundo Palumbo et al., (2010) lesões em pavilhão auricular também podem ser observadas, apesar de ser menos freqüentes.

Otites também podem ser inclusas como manifestações clínicas do LED. Em todos os casos de otites o clínico veterinário deve buscar identificar os fatores predisponentes, causas primárias e perpetuantes, visando oferecer 0 melhor tratamento ao paciente. As causas primárias devem ser sempre estabelecidas para que se descubra a causa da otite externa e alcance o 
FERREIRA FILHO, S.G. et al. Lúpus eritematoso discóide canino: relato de caso. PUBVET, Londrina, V. 8, N. 22, Ed. 271, Art. 1810, Novembro, 2014.

sucesso no tratamento a longo prazo. Como exemplo de causas primárias principais ressalta-se os parasitas (Demodex canis, Otodectes cynotis, carrapatos e pulgas), atopia, distúrbios da ceratinização, hipersensibilidade alimentar e menos comumente doenças auto-imunes, como o LED. Já como fatores predisponentes pode-se citar a conformação dos condutos auditivos, hipertricose auricular, pina pendulosa, trauma por cotonetes, dentre outras. Os principais fatores perpetuantes envolvidos são os microorganismos bacterianos e leveduriformes (SCOTT et al., 1996).

Os principais diagnósticos diferenciais para o LED são: síndrome úveodermatológica, linfoma epiteliotrópico, despigmentação nasal, reação a medicamentos, lúpus eritematoso sistêmico, dermatite nasal solar, pênfigo foliáceo, epidermólise bolhosa, eritema multiforme, dermatomiosite e dermatite de contato (OLIVRY E JACKSON, 2001; GROSS, 2009; SCOTT et al., 1996).

O diagnóstico é firmado baseando-se no exame clínico e biopsia de pele (CONCEIÇÃO et al., 2004; LARSSOM e OTSUKA, 2000; LAWALL et al., 2008; SCOTT et al., 1996). Pesquisa de anticorpos anti-nucleares também pode ser utilizada, mas sua eficácia para o LED é de baixo valor diagnóstico, sendo detectado em apenas 5\% dos casos (GROSS et al., 2009; RHODES, 2003; SCOTT et al., 1996).

As características histopatológicas da pele biopsiada revelam dermatite de interface, seja hidrópica, liquenóide ou mista, ocorrendo edema intracelular (degeneração hidrópica) da camada basal e inúmeros ceratinócitos necrosados na epiderme, já na liquenóide observa-se uma infiltração mononuclear com predomínio plasmocitário adjacente aos vasos e constituintes dermais (ALMEIDA, 2004; GUAGUNÈRE e BENSIGNOR, 2005; GERONYM et al., 2005; RHODES, 2003; SCOTT et al., 1996; VAL, 2006). Pode-se observar ainda comumente no LED mucinose dérmica em vários graus e membrana basal focalmente espessada (RHODES, 2003; SCOTT et al., 1996). 
FERREIRA FILHO, S.G. et al. Lúpus eritematoso discóide canino: relato de caso. PUBVET, Londrina, V. 8, N. 22, Ed. 271, Art. 1810, Novembro, 2014.

\section{RELATO DE CASO:}

Um cão da raça pastor alemão, de 4 anos de idade, foi encaminhado à clinica apresentando histórico de otite bilateral recorrente, crônica e não responsiva ao tratamento com produto otológico contendo enrofloxacina, sulfadiazina de prata e hidrocortisona.

O animal apresentava meneios de cabeça, sensibilidade à palpação e não tolerava exame de otoscopia. Apresentava ainda lesões erodidas em comissuras nasais e despigmentação, sendo que estas não haviam sido notadas pelo proprietário. Não havia lesões em mucosas orais e junções mucocutâneas.

Optou-se por anestesiar o animal, realizar o exame de otoscopia, cultura da secreção otológica, exame citológico da parede do conduto, lavado de ambos os condutos com solução fisiológica e biopsia das lesões erodidas em plano nasal.

O animal foi medicado com acepran e tramadol, sendo posteriormente induzido com propofol, entubado e mantido sob anestesia inalatória com isofluorano.

O exame otoscópico revelou lesões erodidas em ambos os pavilhões auriculares e parede epitelial frágil nos condutos, apresentando também fácil sangramento. Secreção otológica escura foi notada e submetida a exame parasitológico, citológico e de cultura bacteriana. A membrana timpânica mostrava-se íntegra em ambos os ouvidos. Foi realizada lavagem em ambos os pavilhões com solução fisiológica $\mathrm{NaCl} 0,9 \%$, e realizada biópsia das lesões de comissuras nasais com um punch de $5 \mathrm{~mm}$, da periferia da lesão, contendo então na amostra obtida para biópsia, tecido erodido e tecido íntegro, sendo acondicionados em solução contendo formoldeído em concentração de $10 \%$ e encaminhado para laboratório de histopatologia.

O exame citológico revelou Mallassezia pachydermatis incontáveis, o exame parasitológico não revelou presença de ácaros na amostra e o resultado da cultura e antibiograma foi positivo para Staphylococcus pseudointermedius, sendo este sensível a todos os antibióticos de rotina. 
FERREIRA FILHO, S.G. et al. Lúpus eritematoso discóide canino: relato de caso. PUBVET, Londrina, V. 8, N. 22, Ed. 271, Art. 1810, Novembro, 2014.

Macroscopicamente observou-se fragmento de tecido com consistência fibro-elástica medindo $0,4 \mathrm{~cm}$ de diâmetro e apresentando coloração escurecida.

Ao exame histopatológico foi observado tecido apresentando discreto processo de acantose com foco de erosão, notando-se ainda, evidente infiltrado de linfócitos pequenos pela epiderme, principalmente em regiões profundas da mesma (figura 1 A). Em outras porções do epitélio puderam ser constatadas células em processo de apoptose, em camada basal. Incontinência pigmentar esteve presente de forma multifocal moderada. À derme superficial e, principalmente, ao redor de anexos cutâneos, foi visualizado grave infiltrado inflamatório linfoplasmocitário, sendo vistos ocasionais mastócitos associados à lâmina basal da epiderme, sugerindo em associação aos outros achados um caso de LED (figura 1 B).

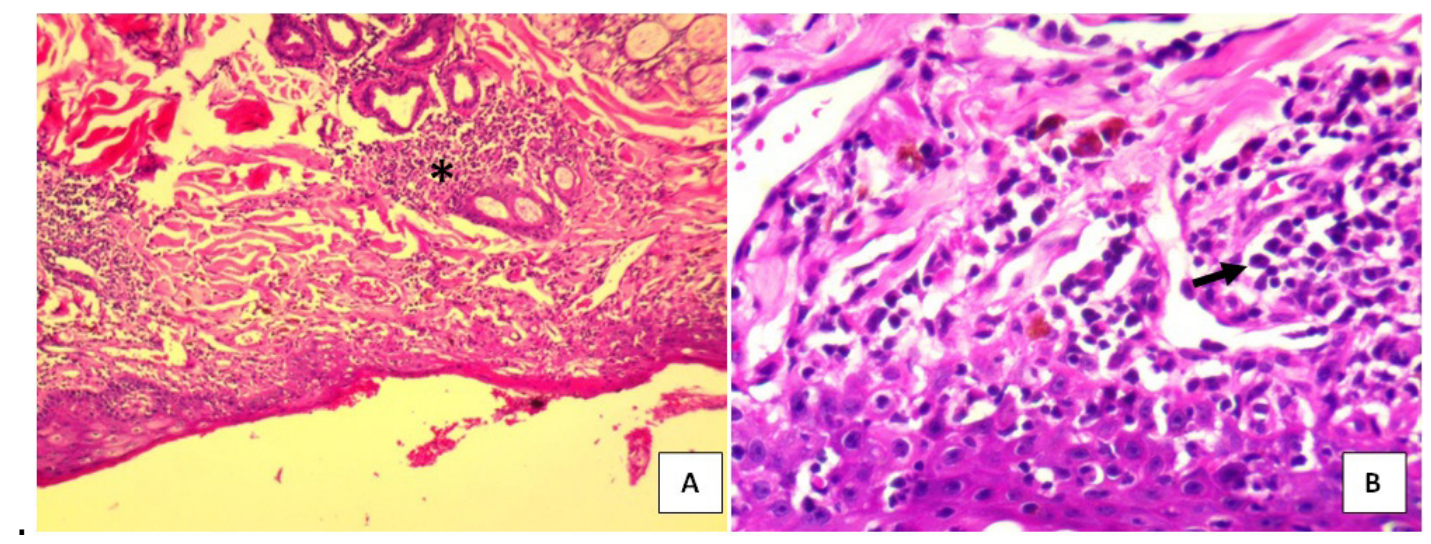

Fonte: Arquivo pessoal

Figura 1: A) Fotomicrografia evidenciando área focalmente extensa de erosão e acentuado infiltrado inflamatório na derme superficial, especialmente na interface, e também na derme profunda, ao redor dos anexos cutâneos (*). (10X) B) Em maior aumento nesta fotomicrografia é possível evidenciar numerosos linfócitos e plasmócitos (seta) caracterizando o infiltrado inflamatório predominante. (40X) 
FERREIRA FILHO, S.G. et al. Lúpus eritematoso discóide canino: relato de caso. PUBVET, Londrina, V. 8, N. 22, Ed. 271, Art. 1810, Novembro, 2014.

A terapia medicamentosa estabelecida foi à base de corticoterapia sistêmica, sendo eleito prednisona na dose de $2 \mathrm{mg} / \mathrm{kg}$, por via oral durante sete dias e corticoterapia tópica com solução aquosa de hidrocortisona a 0,5\% instilada nos condutos auditivos externos. Ainda como terapia medicamentosa tópica, foi utilizado solução comercial contendo enrofloxacino, sulfadiazina de prata e hidrocortisona, na dose de 6 gotas, a cada 12 horas, instilada em ambos condutos auditivos externos, durante 7 dias.

\section{RESULTADOS E DISCUSSÃO:}

Concordando com Rhodes (2003), Scott et al., (1996) e Thompson (1997) que descrevem o pastor alemão como uma raça com uma maior predisposição para o LED, o referido paciente é da raça Pastor Alemão.

O paciente relatado neste trabalho apresentou ao exame físico lesões cutâneas, tais como, crosta, eritema e despigmentação do plano nasal, corroborando com Gerhauser et al., (2006) e Gross et al., (2009) que descrevem estes tipos de lesão no Lúpus Eritematoso Discóide (LED). Já a otite externa auto-imune, apesar de ocorrência mais rara no LED, segundo Gerhauser et al., (2006) e Scott et al., (1996), foi um possível achado importante neste relato de caso, já que o diagnóstico do pavilhão foi presuntivo, associando-o aos achados da histopatologia das comissuras nasais.

Os achados histopatológicos revelam infiltrado linfoplasmocitário em epiderme, derme e anexos cutâneos, concordando com Almeida (2004), Guarnére e Bensignor (2005), Geronym et al., (2005), Rhodes (2003), Scott et al., (1996) e Val (2006) .

O tratamento instituído foi à base de corticoterapia sistêmica com prednisona, empregando-se dose imunossupressora de $2,2 \mathrm{mg} / \mathrm{kg}$ a cada 24 horas por sete dias, demonstrando-se eficiente para regredir as lesões, sendo retirado gradativamente. Scott et al., 1996 relata que em alguns casos pode ser necessário manter a corticoterapia sistêmica com prednisona por até um mês. Já o tratamento tópico instituído foi à base de hidrocortisona a 0,5\%, 
FERREIRA FILHO, S.G. et al. Lúpus eritematoso discóide canino: relato de caso. PUBVET, Londrina, V. 8, N. 22, Ed. 271, Art. 1810, Novembro, 2014.

sendo esta instilada em ambos condutos auditivos externos a cada 12 horas por uso contínuo. De acordo com Scott et al., (1996) a corticoterapia tópica pode ser iniciada à base de corticosteróides de ação longa como a betametasona ou fluocinolona associada ao DMSO, até alcançar completa remissão das lesões, podendo posteriormente, utilizar drogas de menor potência como a hidrocortisona em concentrações de 1 a $2 \%$, espaçando-se ao máximo possível. Todavia, neste caso contradizendo Scott et al., (1996), optou-se por iniciar a corticoterapia tópica com um corticóide de ação rápida à baixa concentração e sem associação ao DMSO, obtendo mesmo assim resultado satisfatório com completa resolução das lesões em plano nasal e da possível causa primária da otite externa. Não houve necessidade de associar outros agentes imunomoduladores sistêmicos, como azatioprina ou clorambucil, já que o paciente alcançou a cura clínica com completa remissão das lesões cutâneas, corroborando com Scott et al., (1996).

De acordo com Scott et al., (1996), deve-se procurar identificar sempre a causa primária de otites. Buscando estabelecer a possível causa primária da otite externa bilateral recorrente, inferiu-se que o LED fosse o responsável, apesar de não ter sido biopsiado o conduto auditivo externo, como sugere este autor.

Citologia dos condutos auditivos externos foi feita para identificar possíveis fatores perpetuantes, conforme recomenda Scott et al., (1996) e incontáveis Malassezias pachydermatis foram identificadas. Este mesmo autor também recomenda produtos comerciais que contenham antibióticos à base de neomicina ou polimixina B e antifúngicos como miconazol $1 \%$ ou clotrimazol, como fármacos de primeira escolha no tratamento de otites bacterianas e fungicas, respectivamente. Porém, por opção financeira do proprietário, que já possuía um produto comercial à base de sulfadiazina de prata, enrofloxacino e hidrocortisona, optou-se por eliminar os fatores perpetuantes utililizando este produto.

Até a presente data o paciente apresenta remissão completa das lesões em plano nasal e não houve recidiva do quadro de otite externa. 
FERREIRA FILHO, S.G. et al. Lúpus eritematoso discóide canino: relato de caso. PUBVET, Londrina, V. 8, N. 22, Ed. 271, Art. 1810, Novembro, 2014.

\section{CONCLUSÃO:}

As doenças auto-imunes apesar de baixa ocorrência na clínica de cães e gatos, quando surgem, exigem do clínico veterinário conhecimento para diagnosticar e conduzir o paciente não só ao diagnóstico, mas também a melhor modalidade terapêutica possível. O LED se caracteriza por ser uma dermatopatia auto-imune de caráter benigno, com diagnóstico baseado nos achados do exame físico e, principalmente histopatologia do tecido afetado, possuindo ainda, prognóstico favorável.

Neste caso relatado apesar de ter sido feito estudo histopatológico somente do plano nasal, suspeitou-se que a otite externa recorrente possuísse relação com o LED, inferindo-se que esta fosse a causa primária da otite, sendo estabelecido tratamento tópico e sistêmico à base de corticosteróides. Apesar da corticoterapia tópica instituída ter sido com corticóide de ação rápida e em baixa concentração, contradizendo a literatura, obteve-se sucesso.

Até a presente data, além da remissão das lesões do plano nasal, o paciente não apresentou recidiva do quadro de otite.

\section{REFERÊNCIAS BIBLIOGRÁFICAS:}

ALMEIDA, E. M. P. Estudo das Características Clínicas e Histomorfométricas da pele de gatos cronicamente exposta ao Sol. Tese (Doutorado) Universidade Estadual de Campinas. Faculdade de Ciência Médicas. Campinas, SP: 2004. Orientador: Maria Letícia Cintra.

BALDA, A. C.; OTSUKA, M.; MICHALANY, N. S.; LARSSON, C. E. Pênfigo foliáceo em cães: levantamento retrospectivo de casos atendidos no período de novembro de 1986 a julho de 2000 e de resposta aos protocolos de terapia empregados no Hospital Veterinário da USP. Revista Brasileira de Ciência Veterinária, Rio de Janeiro, v. 9, n. 2, p. 97-101, 2002.

BERBERT, A. L. C. V.; MANTESE, S. A. O.; Lúpus Eritematoso Cutâneo - Aspectos Clínicos e Laboratoriais. Anais Brasileiros de Dermatologia. p. 80, 2005.

CONCEIÇÃO, L. G. et al. Biópsia e Histopatologia da Pele: um valioso recurso diagnóstico da dermatologia - Revisão parte 1. Clínica Veterinária. n.51, p. 36-44, jul/ago. 2004.

COSTNER, M. I.; SONTHEIMER, R. D. Lupus erythematosus. In: FREEDBERG, I. M. et al. Fitzpatrick's dermatology in general medicine. New York: McGraw-Hill; 2003. p. 1677-93.

FENNER, W. R. Consulta Rápida em Clínica Veterinária. Rio de Janeiro: Guanabara Koogan, 2003.p. 370-371. 
FREITAS, T. H. P.; Proença, N. G. Lúpus eritematoso cutâneo crônico: estudo de 290 pacientes. Anais do Congresso Brasileiro de Dermatologia.p. 78, 2003.

GUARNÈRE, E.; BENSIGNOR, E. Dermatoses Auto-Imunes. In:. Terapêutica Dermatológica do Cão. São Paulo: Rocca, 2005.

GERHAUSER, I.; STROTHMANN-LVERSSEN, A.; BAUMGORTNER, W. A case of interface perianal dermatitis in a dog: is this aunsual manifestation of lupus erythematosus? Veterinary Pathology, Washington, v. 43, n. 5. p. 761-764, 2006.

GERONYM, V. V. et al. Ocorrência de lúpus eritematoso em cães atendidos no hospital veterinário do centro regional universitário de Espírito Santo do Pinhal (Unipinhal), no período de 1999 a 2003. Bol. Med. Vet. - UNIPINHAL - Espírito Santo do Pinhal - SP, v.01, n.01, jan/dez. 2005.

GROOTERS, A. Distúrbios do Sistema Endócrino. In: FENNER, W. R. Consulta Rápida em Clínica Veterinária. Rio de Janeiro: Guanabara Koogan, 3. ed. 2003, p.370-371.

GROSS, T. L. et al. Doenças de pele do cão e do gato - Diagnóstico clínico e histopatológico. 2. ed. São Paulo: Roca, 2009.

IWASAKI, T. et al. Canine case of discoid lupus erythematosus with circulating autoantibody. Journal of Veterinary Medical Science, Tokyo, v. 57, n, 6. p. 1097-1099, 1995.

LARSSOM, C.E.; OTSUKA, M. Lúpus eritematoso discóide -LED: revisão e casuística em serviço especializado na capital de São Paulo. Revista de Educação Continuada do CRMV- SP. São Paulo. v.3, n.1., p.29-36, 2000.

LARSSOM, C. E. Wandering Through the autoimmune dermatoses: Pemphigus Complex. In: WORLD SMALL ANIMAL VETERINARY CONGRESS, 30 th 2005, México. Proceedings of 30 th World Small Animal Veterinary Congress: FECAVA, 2005: Disponível em: http://www.ivis.org/proceedings/wsava/2005/17.pdf. Acesso em: 13 março, 2014, 13:30.

LAWALL, T. et al. Lupus eritematoso discoide em caes - Estudo de três casos clínicos no hospital veterinário da universidade luterana do Brasil nos anos de 2002 a 2008. In: ANAIS DO CONGRESSO BRASILEIRO DE MEDICINA VETERINÁRIA, Gramado, RS, 2008.

NETO, E. F. B.; BONFÁ, E. Lúpus Eritematoso Sistêmico. In: Lopes A. C. Tratado de Clínica Médica. São Paulo: Roca, 2006, p.1595 - 1604.

OLIVRY, T.; JACKSON, H. A. Diagnosing new autoimmune blistering skin diseases of dogs and cats. Clinical Techniques in Small Animal Practice, v.16, n.4, p.225-229, 2001.

PALUMBO, M. I. P. et al. Incidência das dermatopatias auto-imunes em cães e gatos e estudo retrospectivo de 40 casos de lúpus eritematoso discóide atendidos no serviço de dermatologia da Faculdade de Medicina Veterinária e Zootecnia da UNESP - Botucatu. Revista Semina: Ciências Agrárias. Londrina, v. 31, n. 3, p. 739-744, 2010.

ROSEKRANTZ, W.S. Discoid lupus erythematosus. In: GRIFFIN, C.E.: KWOCHKA. K. W.: MACDO ALO. J.M. Current veterinary dermatology. St. Louis: Mosby, 1993. p. 149-153.

RHODES, K. H. Dermatopatias e otopatias: dermatoses imunomediadas. In: BIRCHARD, S. J.; SHERDing, R. G. Manual Saunders: Clínica de Pequenos Animais. 2. ed. São Paulo: Rocca, 2003. 
SCOTT, D. W.; MILLER, W. H.; GRIFFIN, C. E. Dermatologia de Pequenos Animais. Rio de Janeiro: Interlivros, 5. ed. 1996, p. 539-543.

THOMPSON, J. P. Moléstias imunológicas. In: ETTINGER, S. J.; FELDMAN, E. C. Tratado de Medicina Interna Veterinária. 4. ed. São Paulo:Manole, 1997, v2, p.2786-2790.

TIZARD, I. R.. Imunologia Veterinária: introdução. 6 ed. p. 1-154, 175-190, 201; 432437. São Paulo: Roca, 2002.

VAL, A. C. Doenças cutâneas auto-imunes e imunomediadas de maior ocorrência em cães e gatos: revisão de literatura. Clínica Veterinária, n. 60, p 68-74, jan/fev., 2006.

WERNER, A. H. Recognizing and treating discoid lúpus erythematous and pemphigus foliaceus in dog. Veterinary Medicine. Chicago, v. 1, n. 94, p. 955-966, 1999. 